\title{
Effect of recovery from muscle strength imbalance in lower limb using four point weight bearing reduction system
}

\author{
Chang Ho Yu ${ }^{\mathrm{a}}$, Seung Rok Kang ${ }^{\mathrm{b}}$, Ho Choon Jeong ${ }^{\mathrm{c}}$, Kyung Kim ${ }^{\mathrm{d}}$ and Tae Kyu Kwon ${ }^{\mathrm{a}, *}$ \\ ${ }^{a}$ Division of Biomedical Engineering, Chonbuk National University, 567 Baekje-daero, Deokjin-gu, \\ Jeonju-si, Jeonbuk 561-756, Republic of Korea \\ ${ }^{b}$ Department of Healthcare Engineering, Chonbuk National University, 567 Baekje-daero, Deokjin- \\ gu, Jeonju-si, Jeonbuk 561-756, Republic of Korea \\ ${ }^{c}$ CyberMedic Co, 20-23 Yakchon-ro 8-gil, Iksan-si, Jeonbuk 570-979, Republic of Korea. \\ ${ }^{d}$ Chonbuk National University Automobile-parts \& mold Technology Innovation Center, 67 Yusang-ro, \\ Deokjin-gu, Jeonju-si, Jeonbuk 561-844, Republic of Korea
}

\begin{abstract}
This study was performed to assess the improvement of muscle strength imbalance in the lower limbs using a four point weight bearing reduction system with a two-belt treadmill. Participants, each having differences in muscle function of the left and right legs of over $20 \%$, were divided into two groups of ten. The participants were involved in experiments progressing 40 minutes per day, 3 days per week, during a period of 4 weeks. The maximal peak torque and average power were measured for testing joint torque in the hip, knee and ankle. The results showed the improvement of muscle imbalance as assessed by the maximal muscle strength was the most effective in the hip joint, while the improvement of muscular reaction was the most effective in the knee joint. We suggest that the method of weight bearing reduction could be sufficient to reduce muscle imbalance in the lower limbs.
\end{abstract}

Keywords: Reduction of weight bearing, joint torque, gait, muscle imbalance, two-belt treadmill

\section{Introduction}

Recently, the number of people with muscle imbalance in the lower limbs is increasing, and among these, except for those with congenital anatomical problems, most of such imbalance is attributable to incorrect exercise posture or life style [1]. Generally, incorrect exercise posture or life style repeated unconsciously can cause significant bodily deformation [2]. Particularly, in the case of lower limbs, when standing obliquely by using the dominant leg frequently as support or loading more momentum on one leg compared with the other during exercise, muscle imbalance is caused.

\footnotetext{
${ }^{*}$ Corresponding author: Tae Kyu Kwon, Division of Biomedical Engineering, Chonbuk National University, 567 Baekjedaero, Deokjin-gu, Jeonju-si, Jeonbuk 561-756, Republic of Korea. Tel.: +82-63-270-4066; Fax: +82-63-270-2247; E-mail: kwon10@jbnu.ac.kr.
} 
These days, most sports equipment can cause muscle imbalance, as it was developed with the focus of increasing muscle strength [3]. Muscle imbalance caused thereby may induce skeletal deformation and musculoskeletal diseases, and may lead to chronic disease. In particular, the lower limbs are a part that affects postural stability, and the frequency of musculoskeletal injury or disease is high. As it applies a lot of load to the body, imbalance of the lower limbs may cause serious injury to the trunk or lumbar vertebra due to a general reduction in body balance [4].

Presently, study on muscle imbalance has extensively progressed in terms of the prediction of exercise injury or effects of rehabilitation, specifically targeting athletes. It was reported that if there is a difference of over $10 \%$ in the muscle strength of the quadriceps femoris of the left/right limbs, the frequency of injury in athletes is increased [5]. If the balance ratio of left/right muscle strength in domestic elite athletes is over $10 \%$, the possibility of injury was evaluated to be high [6]. Overseas, it was reported that muscle strength imbalance over $8 \%$ is positively acknowledged, while imbalance over $10 \%$ increases the rate of exercise-related injury [7]. In addition to these results, studies targeting the general population and the aged have also progressed extensively. During gait of the elderly, muscle strength imbalance of the lower limbs was reported to cause the time of the simultaneously supporting limb on the ground to increase in order to compensate for the side with weak muscle strength [8]. However, as there are fewer kinds of musculoskeletal diseases and smaller numbers of patients with diseases of the lower limbs than the upper limbs, most studies have been limited to the upper limbs and trunk, so a systematic study on musculoskeletal diseases by examining muscle strength imbalance is not sufficient in reality $[9,10]$. In addition, the existing preceding studies focused only on an effect of muscle strength imbalance of lower limbs on the human body or on a method of evaluation, while little research on improving such practice has been reported.

Therefore, in this study, we are going to consider an effect of improvement to muscle imbalance in lower limb according to reduction of weight bearing of horizontal shaft during left/right individual gait.

\section{Experimental methods}

\subsection{Subjects}

In order to select test participants with lower limb imbalance, 100 adult males/females were randomly selected. Of these, 20 people who showed a difference of the left/right muscle strength of the hip joint, knee joint and ankle joint over $20 \%$ were selected by testing joint torque (Biodex system3, Biodex medical science Ltd., NY, USA). Before experimentation, the 20 selected participants were randomly divided into 2 experiment groups of 10 people: the weight bearing reduction gait group (NWB, non-weight bearing group), and the control group of general gait (WB, weight bearing group) (Table 1). In addition, all the test participants possessed stronger muscle strength in the right leg than the left leg.

\subsection{Experimental equipment}

The four-point weight bearing reduction system is a piece of equipment which provides a reduction in weight bearing in the horizontal direction through 2 front shafts and 2 left/right shafts. While the existing horizontal shaft system provided reduction in weight bearing through a suspension system in the form of wire, a suspension system in the form of a bicycle saddle was applied in the system tested herein. Contrary to the existing system, weight bearing reduction was provided in a form that does not 
have outside binding force of upper and lower limbs. In addition, the reduction rate is provided based on $1 \%$ per weight of the test subject, and the bearing reduction function was provided from $1-100 \%$, with real time visual/auditory feedback functions. In addition, a two-belt treadmill was attached in an integrated type, with the left/right side providing gait speed independently (Figure 1).

Table 1

Physical results showing maximal peak torque in hip, knee and ankle joint of the selected participants during pre-test

\begin{tabular}{|l|l|l|l|l|l|l|l|l|}
\hline & \multicolumn{4}{|l|}{ Weight Bearing group(WB) } & \multicolumn{4}{l|}{ Non-Weight Bearing group(NWB) } \\
\hline $\begin{array}{l}\text { Joint tor- } \\
\text { que(Nm) }\end{array}$ & Left & Right & $\begin{array}{l}\text { Differ- } \\
\text { ence }\end{array}$ & $\begin{array}{l}\text { Percen- } \\
\text { tage(\%) }\end{array}$ & Left & Right & Difference & $\begin{array}{l}\text { Percen- } \\
\text { tage(\%) }\end{array}$ \\
\hline Hip & $70.3 \pm 2.9$ & $84.8 \pm 1.9$ & $14.5 \pm 3.2$ & 20.6 & $72.4 \pm 3.3$ & $88.8 \pm 2.6$ & $16.4 \pm 1.7$ & 22.6 \\
\hline Knee & $80.6 \pm 4.4$ & $98.9 \pm 5.1$ & $18.2 \pm 3.6$ & 22.4 & $79.5 \pm 3.3$ & $97.5 \pm 4.1$ & $18.0 \pm 3.0$ & 22.5 \\
\hline Ankle & $40.4 \pm 4.0$ & $50.6 \pm 3.7$ & $10.0 \pm 1.8$ & 24.8 & $43.5 \pm 3.2$ & $52.6 \pm 2.7$ & $9.2 \pm 1.2$ & 21.7 \\
\hline
\end{tabular}

Table 2

Results of the ratings of perceived exertion according to gait velocity with left and right leg (scores: scored as difficulty during exercise; scale: subject's feelings of difficulty; gait velocity: gait speed of the treadmill; Subjects with pain: number of subjects experiencing pain)

\begin{tabular}{|l|l|l|l|l|l|}
\hline \multicolumn{2}{|l|}{ Borg PRE scale } & \multicolumn{2}{l|}{$\begin{array}{l}\text { Gait velocity } \\
(\mathrm{km} / \mathrm{h})\end{array}$} & \multicolumn{2}{l|}{ PRE result during gait } \\
\hline Scores & Scale & Left & Right & PRE score & Number of pain \\
\hline 7 & very, very light & 3.3 & 3 & $7.5 \pm 1.2$ & 0 \\
\hline 9 & very right & 3.4 & 3 & $7.5 \pm 1.5$ & 0 \\
\hline 11 & fairly light & 3.5 & 3 & $10.8 \pm 1.1$ & 0 \\
\hline 13 & somewhat hard & 3.6 & 3 & $10.8 \pm 2.7$ & 0 \\
\hline 15 & Hard & 3.7 & 3 & $12.3 \pm 1.4$ & 0 \\
\hline 17 & very hard & 3.8 & 3 & $12.9 \pm 1.9$ & 0 \\
\hline 19 & very, very hard & 3.9 & 3 & $15.7 \pm 2.0$ & 0 \\
\hline 20 & maximum exertion & 4.0 & 3 & $18.9 \pm 1.5$ & 8 \\
\hline
\end{tabular}

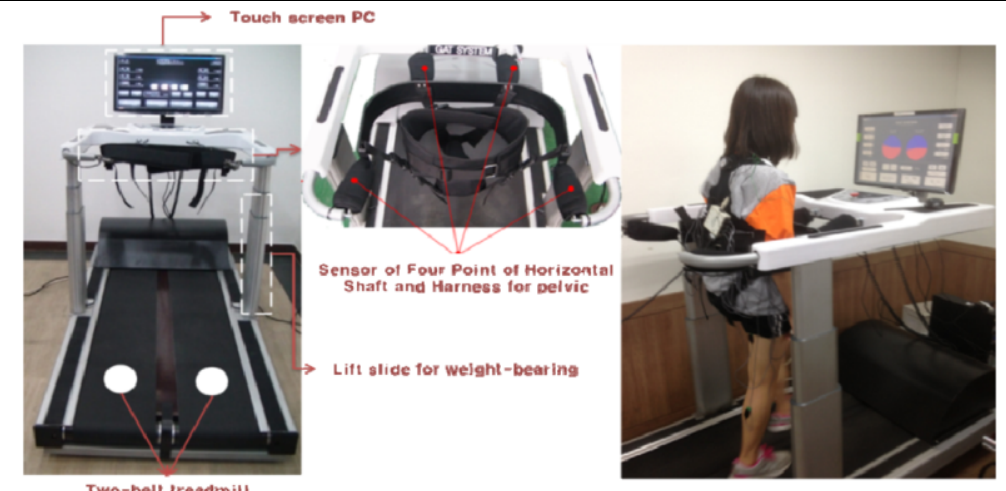

(a)

(b)

Fig. 1. Test configuration: (a) Four point weight bearing reduction system based on a two-belt treadmill; GAT, Cybermedic Co. Ltd., Korea. (b) Gait by weight bearing using the system. 


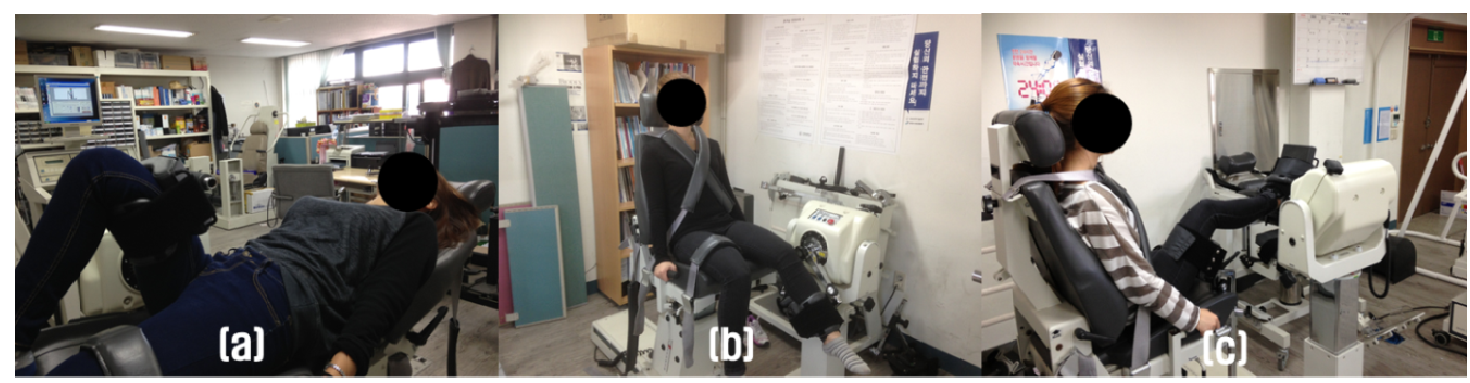

Fig. 2. Isokinetic joint torque test for estimating correction effect of muscle imbalance in lower limbs ((a) hip joint, (b) knee joint, (c) ankle joint).

\subsection{Procedure and method of experiment}

Using the four point weight bearing system, test participants performed walking exercise every other day, 3 times a week, and the left/right gait speed of the two-belt treadmill was independently provided. The left/right independent gait speed was equally provided to the two groups through PRE (Ratings of perceived exertion) of the test participants before the test. PRE is a numerical representation of the exercise strength felt by test participants while exercising, and the rating is performed by dividing into 6-20 stages [11]. PRE for the left/right independent gait speed was evaluated for the test participants before the test. For the leg with dominant muscle strength, the PRE was performed based on a speed of $3 \mathrm{~km} / \mathrm{h}$, ordinary gait speed, while the gait speed was set at $3.9 \mathrm{~km} / \mathrm{h}$ in the other leg, which is the gait speed of the pre-stage of the section where pain is felt during walking (Table 2).

The experiment group was provided with a $50 \%$ reduction of participant's weight provided by the system. In order to explore the correction of muscle strength imbalance in the lower limbs, isokinetic joint torque was measured twice every 2 weeks, for a total of 4 weeks (Figure 2). The joint torque test protocol included the knee joint extensor, and plantar flexion of the ankle joint. In addition, the maximal peak torque, muscle reaction, and average power were evaluated in order to analyze the maximal muscle strength variation [12]. At the time of evaluating the walking exercise and isokinetic joint torque, environmental test error was minimized by maintaining a temperature of $19 \pm 2.1^{\circ} \mathrm{C}$ and humidity of $50 \pm 5.7 \%[13]$.

\subsection{Data analysis}

In order to analyze the correction of left/right muscle strength imbalance in the lower limbs according to status of weight bearing reduction, the maximal peak torque by each joint, average power and standard deviation were estimated using SPSS 18. In addition, a paired t-test was performed to verify the pre/post effect of walking exercises by group, with a significance level of $* p<0.05$.

\section{Results and discussion}

3.1. Variation of maximal muscle strength and muscle reaction time in hip joint according to status of weight bearing reduction

Before the test, the control group had a left/right maximal muscle strength difference of $20.6 \%$ in 
the hip joint (WB: $14.5 \pm 2.1 \mathrm{Nm}$ ), while that of the experiment group was $22.6 \%$ (NWB: $16.4 \pm 3.1$ $\mathrm{Nm})$. Similar left/right muscle strength imbalance was represented in the two groups. A significant difference was not observed after 2 weeks of training, but a mutually different tendency was observed after 4 weeks. Both groups showed minor differences in the level of approximately $2 \%$ after 2 weeks; however, decreases down to $9.9 \%$ in the experiment group were observed after 4 weeks (NWB: $9.6 \pm 2.7 \mathrm{Nm}$ ), representing a $12.51 \%$ correction of the imbalance. The most significant correction was observed in the knee joint and ankle joint. In contrast, rather than decreasing in the control group, it increased up to $28.2 \%$ (WB: $23.0 \pm 4.9 \mathrm{Nm}$ ), representing aggravation of the imbalance by $7.6 \%$, representing a significant difference (Table 3 ).

Average power showed a similar trend as the maximal muscle strength, decreasing from $20.5 \%$ (NWB: $6.4 \pm 2.5$ watts) before the test to $5.9 \%$ after the test in the experiment group. In contrast, an increase from $19.4 \%$ (WB: $5.8 \pm 1.0$ watts) before the test to $21.1 \%$ after the test was observed (Table 3). Weight bearing by the hip joint takes place after mid stance during a stride, at which time the weight bearing amounts to approximately 4 times the level of weight. It was judged that significant weight loaded on the hip joint compared with the knee joint and ankle joint during walking exercise caused an increase of the muscle strength imbalance. In other words, it was considered that the reduction of weight bearing by the hip joint during two-belt treadmill gait was achieved, providing a positive effect for correcting the left/right muscle strength imbalance. However, it should be noted that there is a possibility of causing an aggravation of the muscle strength imbalance when using left/right independent gait speed without weight bearing.

Table 3

The results of maximal peak torque and average power of hip joint by adapting the weight bearing reduction method in groups [joint torque in period: Mean $\pm \mathrm{SD}$ (standard deviation), $\mathrm{p}<0.05$ ]

\begin{tabular}{|c|c|c|c|c|c|}
\hline \multirow{2}{*}{ Group } & \multirow{2}{*}{\multicolumn{2}{|c|}{ Protocol }} & \multicolumn{3}{|c|}{ Joint torque in period } \\
\hline & & & \multirow{2}{*}{$\begin{array}{l}0 \text {-week } \\
70.3 \pm 3.5\end{array}$} & 2-week & \multirow{2}{*}{$\begin{array}{l}\text { 4-week } \\
81.3 \pm 4.6\end{array}$} \\
\hline \multirow{8}{*}{$\begin{array}{l}\text { Weight } \\
\text { bearing } \\
\text { group }\end{array}$} & \multirow{4}{*}{$\begin{array}{l}\text { Maximal peak } \\
\text { torque(Nm) }\end{array}$} & Left & & $77.1 \pm 2.5$ & \\
\hline & & Right & $84.4 \pm 7.5$ & $93.2 \pm 6.5$ & $104.3 \pm 7.7$ \\
\hline & & Difference[\%] & $14.5 \pm 2.1[20.6]$ & $16.1 \pm 1.7[20.9]$ & $23.0 \pm 4.9[28.2]$ \\
\hline & & P-value & \multicolumn{2}{|r|}{0.01} & \\
\hline & \multirow{4}{*}{$\begin{array}{l}\text { Average pow- } \\
\text { er(watts) }\end{array}$} & Left & $30.2 \pm 1.2$ & $32.4 \pm 0.4$ & $33.3 \pm 3.1$ \\
\hline & & Right & $36.0 \pm 2.1$ & $39.1 \pm 4.6$ & $40.2 \pm 1.9$ \\
\hline & & Difference[\%] & $5.8 \pm 1.0[19.4]$ & $6.7 \pm 2.1[20.9]$ & $7.0 \pm 2.1[21.1]$ \\
\hline & & P-value & \multicolumn{2}{|r|}{0.00} & \\
\hline \multirow{8}{*}{$\begin{array}{l}\text { None- } \\
\text { weight bear- } \\
\text { ing group }\end{array}$} & \multirow{4}{*}{$\begin{array}{l}\text { Maximal peak } \\
\text { torque }(\mathrm{Nm})\end{array}$} & Left & $72.4 \pm 6.5$ & $88.3 \pm 9.2$ & $96.8 \pm 5.1$ \\
\hline & & Right & $88.8 \pm 2.2$ & $100.2 \pm 4.6$ & $106.4 \pm 6.5$ \\
\hline & & Difference[\%] & $16.4 \pm 3.1[22.6]$ & $12.0 \pm 3.0[13.6]$ & $9.6 \pm 2.7[9.9]$ \\
\hline & & P-value & \multicolumn{2}{|l|}{0.01} & \\
\hline & \multirow{4}{*}{$\begin{array}{l}\text { Average pow- } \\
\text { er(watts) }\end{array}$} & Left & $30.9 \pm 3.1$ & $35.3 \pm 2.2$ & $40.5 \pm 2.8$ \\
\hline & & Right & $37.2 \pm 1.9$ & $40.3 \pm 3.5$ & $42.9 \pm 3.6$ \\
\hline & & Difference[\%] & $6.4 \pm 2.5[20.5]$ & $5.0 \pm 1.1[14.1]$ & $2.4 \pm 0.9[5.9]$ \\
\hline & & P-value & \multicolumn{2}{|r|}{0.00} & \\
\hline
\end{tabular}


Table 4

The results of maximal peak torque and average power of knee joint by adapting the weight bearing reduction method in groups [joint torque in period: Mean $\pm \mathrm{SD}$ (standard deviation), $\mathrm{p}<0.05$ ]

\begin{tabular}{|c|c|c|c|c|c|}
\hline \multirow{2}{*}{ Group } & \multirow{2}{*}{\multicolumn{2}{|c|}{ Protocol }} & \multicolumn{3}{|c|}{ Joint torque in period } \\
\hline & & & \multirow{2}{*}{$\begin{array}{l}0 \text {-week } \\
80.6 \pm 5.0\end{array}$} & 2-week & \multirow{2}{*}{$\begin{array}{l}\text { 4-week } \\
88.1 \pm 5.1\end{array}$} \\
\hline \multirow{8}{*}{$\begin{array}{l}\text { Weight } \\
\text { bearing } \\
\text { group }\end{array}$} & \multirow{4}{*}{$\begin{array}{l}\text { Maximal peak } \\
\text { torque(Nm) }\end{array}$} & Left & & $87.6 \pm 9.8$ & \\
\hline & & Right & $98.9 \pm 9.4$ & $108.7 \pm 10.7$ & $112.3 \pm 5.6$ \\
\hline & & Difference[\%] & $18.2 \pm 3.5[22.6]$ & $20.9 \pm 3.4[23.9]$ & $24.2 \pm 3.3[27.4]$ \\
\hline & & $\mathrm{P}$-value & \multicolumn{2}{|l|}{0.00} & 0.01 \\
\hline & \multirow{4}{*}{$\begin{array}{l}\text { Average pow- } \\
\text { er(watts) }\end{array}$} & Left & $71.5 \pm 3.4$ & $73.3 \pm 5.6$ & $75.2 \pm 1.2$ \\
\hline & & Right & $86.4 \pm 4.2$ & $88.7 \pm 7.5$ & $94.7 \pm 4.5$ \\
\hline & & Difference[\%] & $14.9 \pm 3.3[20.1]$ & $15.4 \pm 3.0[21.0]$ & $19.4 \pm 4.2[25.7]$ \\
\hline & & P-value & 0.01 & 0.02 & \\
\hline \multirow{8}{*}{$\begin{array}{l}\text { None- } \\
\text { weight bear- } \\
\text { ing group }\end{array}$} & \multirow{4}{*}{$\begin{array}{l}\text { Maximal peak } \\
\text { torque(Nm) }\end{array}$} & Left & $79.5 \pm 3.0$ & $85.1 \pm 7.8$ & $94.6 \pm 10.1$ \\
\hline & & Right & $97.5 \pm 4.4$ & $103.2 \pm 3.7$ & $106.3 \pm 6.6$ \\
\hline & & Difference[\%] & $18.0 \pm 3.1[22.5]$ & $18.1 \pm 2.8[21.2]$ & $11.7 \pm 2.5[12.3]$ \\
\hline & & $\mathrm{P}$-value & \multicolumn{2}{|l|}{0.00} & \\
\hline & \multirow{4}{*}{$\begin{array}{l}\text { Average pow- } \\
\text { er(watts) }\end{array}$} & Left & $70.3 \pm 1.4$ & $74.1 \pm 1.3$ & $80.1 \pm 3.6$ \\
\hline & & Right & $88.3 \pm 3.5$ & $90.2 \pm 6.1$ & $91.3 \pm 2.9$ \\
\hline & & Difference[\%] & $18.1 \pm 2.4[25.7]$ & $16.2 \pm 3.7[21.8]$ & $11.1 \pm 3.0[13.8]$ \\
\hline & & P-value & \multicolumn{2}{|r|}{0.00} & \\
\hline
\end{tabular}

\subsection{Variation of maximal muscle strength and muscle reaction time in knee joint according to status of weight bearing reduction}

For the knee joint, the control group (WB: $22.6 \%$ : $18.2 \pm 3.5 \mathrm{Nm}$ ) and experiment group (NWB, 22.5\%: $18.0 \pm 3.1 \mathrm{Nm}$ ) showed similar muscle strength imbalance indicated by the maximal muscle strength difference before the test. Similar to the results for the hip joint, the difference between the two groups was almost negligible after 2 weeks the experiment, but significant differences were observed after 4 weeks. The experiment group had decreases down to $12.3 \%$ (NWB: $11.7 \pm 2.5 \mathrm{Nm}$ ), representing a $10.2 \%$ correction of the imbalance. However, the control group was measured at $27.4 \%$ (WB: $24.2 \pm 3.3 \mathrm{Nm}$ ), showing an increasing trend of $4.8 \%$, similar to the result of aggravation of the imbalance observed for the hip joint (Table 4). In the case of average power, the experimental group decreased from $25.7 \%$ (NWB: $18.1 \pm 2.4$ watts) before the test to $13.8 \%$ after, showing significant correction. In addition, similar to the results for the hip joint, imbalance of the control group showed a tendency of approximately $5.6 \%$ increase (Table 4 ).

The knee joint was the most significantly affected by the quadriceps femoris and hamstring, and these muscles are mostly mobilized during lower limb movement by generating strong force among the muscles. In particular, as the hamstring plays the role of flexion and open motor chain of rotation of the knee joint, it is important for leg positioning and exercise. It was considered that the reason the maximal muscle strength of the knee joint showed less correction than the hip joint was that during gait, the tibiofemoral joint force acts at 1.6 times the weight. However, as a result of the muscle reaction, the knee joint showed significant correction, which may be because the ligament, joint capsule 
and other soft tissue of the knee joint have plenty of sensory nerve fibers and receptors. Furthermore, as the muscles relevant to the knee joint provide absorption activity to protect against impact during jumping or landing, it is a site exposed to frequent injury, among which anterior cruciate ligament rupture is a typical case $[14,15]$. It was judged that the weight bearing reduction method would provide a positive effect together with pain reduction during gait rehabilitation therapy to patients with anterior cruciate ligament rupture.

\subsection{Variation of maximal muscle strength and muscle reaction time in ankle joint according to status of weight bearing reduction}

Before the test, the maximal muscle strength difference of the ankle joint was $21.5 \%$ (WB: $8.7 \pm 1.6$ $\mathrm{Nm}$ ) in the control group and $21.1 \%$ (NWB: $9.2 \pm 2.0 \mathrm{Nm}$ ) in the experiment group, representing similar left/right muscle strength imbalance. Contrary to the observations for the hip and knee joint, the muscle imbalance (NWB, 14.6\%: 8.6 $1.9 \mathrm{Nm}$ ) in the ankle joint showed a tendency to decrease significantly in the experiment group after only 2 weeks of the experiment. After the test was completed, it decreased to $12.6 \%$ (NWB: $8.9 \pm 1.3 \mathrm{Nm}$ ) in the experiment group, but increased to $29.8 \%$ in the control group, showing an increase of $8.3 \%$ (Table 5). The results of average power were similar to the hip and knee joint, showing a correction of imbalance of approximately $6.1 \%$ after 4 weeks (Table 5). This improvement was observed because the gastrocnemius and soleus muscles, which generate motor momentum during gait, are the posterior muscles of the ankle joint and play a significant role in postural sway or ankle stabilization during gait, thus are significantly affected by weight bearing when supporting the body. From the results of this experiment, it was judged that the reduction of muscle strength caused by weight bearing reduction minimizes the weight bearing, while maximizing muscle strengthening.

Table 5

The results of maximal peak torque and average power of ankle joint by adapting the weight bearing reduction method in groups [joint torque in period: Mean $\pm \mathrm{SD}$ (standard deviation), $\mathrm{p}<0.05$ ]

\begin{tabular}{|c|c|c|c|c|c|}
\hline \multirow{2}{*}{ Group } & \multirow{2}{*}{\multicolumn{2}{|c|}{ Protocol }} & \multicolumn{3}{|c|}{ Joint torque in period } \\
\hline & & & \multirow{2}{*}{$\begin{array}{l}0 \text {-week } \\
40.3 \pm 2.5\end{array}$} & 2-week & \multirow{2}{*}{$\begin{array}{l}\text { 4-week } \\
59.4 \pm 2.1\end{array}$} \\
\hline \multirow{8}{*}{$\begin{array}{l}\text { Weight } \\
\text { bearing } \\
\text { group }\end{array}$} & \multirow{4}{*}{$\begin{array}{l}\text { Maximal peak } \\
\text { torque }(\mathrm{Nm})\end{array}$} & Left & & $56.4 \pm 6.1$ & \\
\hline & & Right & $49.0 \pm 6.4$ & $70.0 \pm 4.2$ & $77.1 \pm 6.2$ \\
\hline & & Difference[\%] & $8.7 \pm 1.6[21.5]$ & $13.6 \pm 2.8[24.2]$ & $17.7 \pm 3.8[29.8]$ \\
\hline & & P-value & \multicolumn{2}{|r|}{\begin{tabular}{l|l} 
& 0.00 \\
\end{tabular}} & \\
\hline & \multirow{4}{*}{$\begin{array}{l}\text { Average pow- } \\
\text { er(watts) }\end{array}$} & Left & $17.4 \pm 2.2$ & $18.0 \pm 1.9$ & $22.3 \pm 2.1$ \\
\hline & & Right & $20.2 \pm 1.5$ & $21.3 \pm 2.0$ & $27.6 \pm 0.6$ \\
\hline & & Difference[\%] & $2.8 \pm 1.1[16.4]$ & $3.3 \pm 0.9[18.3]$ & $5.3 \pm 1.0[23.8]$ \\
\hline & & $\mathrm{P}$-value & 0.00 & 0.01 & \\
\hline \multirow{8}{*}{$\begin{array}{l}\text { None- } \\
\text { weight bear- } \\
\text { ing group }\end{array}$} & \multirow{4}{*}{$\begin{array}{l}\text { Maximal peak } \\
\text { torque }(\mathrm{Nm})\end{array}$} & Left & $43.5 \pm 4.2$ & $59.4 \pm 3.1$ & $70.4 \pm 7.2$ \\
\hline & & Right & $52.7 \pm 1.2$ & $68.0 \pm 4.5$ & $79.3 \pm 3.1$ \\
\hline & & Difference[\%] & $9.2 \pm 2.0[21.1]$ & $8.6 \pm 1.9[14.6]$ & $8.9 \pm 1.3[12.6]$ \\
\hline & & P-value & 0.01 & 0.00 & \\
\hline & \multirow{4}{*}{$\begin{array}{l}\text { Average pow- } \\
\text { er(watts) }\end{array}$} & Left & $18.3 \pm 3.2$ & $20.1 \pm 1.2$ & $22.9 \pm 1.9$ \\
\hline & & Right & $21.9 \pm 3.0$ & $23.6 \pm 2.1$ & $26.1 \pm 1.2$ \\
\hline & & Difference[\%] & $3.5 \pm 0.9[19.9]$ & $3.5 \pm 0.9[17.4]$ & $3.1 \pm 0.8[13.8]$ \\
\hline & & $\mathrm{P}$-value & 0.00 & 0.00 & \\
\hline
\end{tabular}




\section{Conclusion}

This study analyzed the correction of muscle strength imbalance in the lower limbs according to weight bearing reduction in the horizontal shaft achieved by walking on a two-belt treadmill with left/right individual gait. As a result, the following conclusions were obtained.

The left/right independent gait provided with weight bearing reduction significantly decreased the muscle strength differences of the maximal muscle strength and muscle reaction of the hip joint, knee joint and ankle joint after 4 weeks of experimentation, showing significant correction of the muscle strength imbalance. In particular, as weight bearing is significantly loaded on the hip joint during gait, the correction of muscle strength imbalance was the most effective for the hip joint. In addition, as the knee joint has plenty of sensory nerve fibers and receptors, it showed the most significant effect in correction of left/right muscle reaction imbalance.

However, as the muscle strength imbalance had a tendency to increase rather than decrease when independent gait speed was used without weight bearing reduction, the weight bearing reduction should definitely be applied at the time of treatment of muscle strength imbalance.

\section{Acknowledgment}

This work was supported by Ministry of Trade, Industry \& Energy (MOTIE) (QoLT Technology Development, No. 10048001) and partially supported by the Sports Promotion Fund of Seoul Olympic Sports Promotion Foundation from Ministry of Culture, Sports and Tourism.

\section{References}

[1] L.M. Nashner, Evaluation of postural stability, movement, and control, in: Clinical Exercise Physiology, S.M. Hasson, ed., St. Louis, Mosby, 1994, pp. 199-234.

[2] S.R. Kang, G.Y. Jung, D.A. Moon, J.S. Jeong, J.J. Kim and T.K. Kwon, Evaluation of Bio-mechanical characteristics according to loading deviation methods during rowing exercise, Korean Journal of Sport Biomechanics 21 (2011), 369382.

[3] S.R. Kang, S.B. Seo, G.Y. Jeong, J.J. Bae, C.H. Yu, M. Yu, D.A. Moon, J.S. Jeong and T.K. Kwon, Effect on improvement of muscle strength imbalance according to load deviation pattern of left and right arms in upper limbs, Journal of the Korean Society for Precision Engineering 29 (2012), 1026-1034.

[4] I.S. Lee and M.G. Chung, Workload evaluation of squatting work postures, Journal of the Korean Institute of Industrial Engineers 24 (1998), 167-173.

[5] C. Askling, J. Karlsson and A. Thorstensson, Hamstring injury occurrence in elite soccer players after preseason strength training with eccentric overload, Scandinavian Journal of Medicine and Science in Sports 13 (2003), 244-250.

[6] Y.J. Moon, Analysis of imbalance of left/right muscle strength at the time of snatch motion in weightlifting and development of its therapeutic program, Korea Sports Promotion Foundation, Seoul, 2006, pp. 1-49.

[7] R.U. Newton, A. Gerber, S. Nimphius, J.K. Shim, B.K Doan, M. Robertson, D.R. Pearson, B.W. Craig, K. Häkkinen and W.J. Kraemer, Determination of functional strength imbalance of the lower extremities, Journal of Strength and Conditional Research 20 (2006), 971-997.

[8] Y.S. Park and S.N. Lee, An analysis of gait variables by muscle strength imbalance of low extremity and descent-stair walking in elderly women, The Korean Journal of Growth and Motor Development 20 (2012), 127-132.

[9] A.M. Genaidy, A.A. Al-shedi and W. Karwowski, Postural stress analysis in industry, Applied Ergonomics 25 (1994), 77-87.

[10] E.S. Kim, An ergonomic evaluation of workload in imbalanced lower limbs postures, Master Thesis, University of Dong-A, 2010. 
[11] T. Jürimäea, J.A. Perez-Turpinb, J.M. Cortell-Tormob, I.J. Chinchilla-Mirab, R. Cejuela-Antab, J. Mäestua, P. Purgea and J. Jürimäe, Relationship between rowing ergometer performance and physiological responses to upper and lower body exercises in rowers, Journal of Science and Medicine in Sport 14 (2010), 434-437.

[12] S.R. Kang, K. Kim, G.Y. Jeong, D.A. Moon and T.K. Kwon, Characteristic analysis of flexibility and muscle strength according to exercise using lumbar strengthen exercise instrument, Journal of Rehabilitation Welfare Engineering \& Assistive Technology 4 (2010), 55-63.

[13] S.R. Kang, U.R. Kim, G.Y. Jeong, D.A. Moon and T.K. Kwon, Analysis on the flexibility and muscle function in young adults using indoor horseback riding machine, Journal of Rehabilitation Welfare Engineering \& Assistive Technology 7 (2013), 1-11.

[14] R.J. Schmitz, H. Kim and S.J. Shultz, Effect of axial load on anterior tibial translation when transitioning from nonweight bearing to weight bearing, Clinical Biomechanics 25 (2010), 77-82.

[15] M.J. Mueller, L.J. Tuttle, J.W. LeMaster, M.J. Strube, J.B. McGill, M.K. Hastings and D.R. Sinacore, Weight-bearing versus non weight-bearing exercise for persons with diabetes and peripheral neuropathy: A randomized controlled Trial, Clinical Biomechanics 9 (2013), 829-838. 